J. Neurol. Neurosurg. Psychiat., 1955, 18, 137.

\title{
USE OF DEHYDROISOANDROSTERONE IN PSYCHIATRIC PRACTICE*
}

\author{
BY \\ E. B. STRAUSS and W. A. H. STEVENSON \\ From the Department of Psychological Medicine, St. Bartholomew's Hospital, London
}

Having made a preliminary survey of the effect of dehydroisoandrosterone in selected cases of schizophrenia and schizoid psychopathy we decided to investigate a selected group of 11 patients who, irrespective of age, exhibited constitutional immaturity (especially at the emotional level) and who appeared to be inadequate but not psychotic. The patients had previously received psychiatric treatment of one sort or another, but all psychotherapy was avoided so far as possible during treatment, except in Cases 8 and 9 : interviews were restricted to the recording of subjective and objective findings.

Preliminary investigations always included a routine physical examination and urine test, and, where possible, the total 24-hour 17-ketosteroid output, together with an evaluation of the alpha and beta factors, was estimated. (In quite a number of cases the total was low, or the beta factor diminished.) Estimations of the white cell count, differential count, weight, and blood pressure were done in some cases before treatment, and repeated at intervals during treatment, together with a repetition of the total 17-ketosteroid estimation. Wherever possible a Rorschach test was carried out before treatment and repeated after a significant period of medication.

Organon Laboratories supplied tablets, each containing $10 \mathrm{mg}$. of epi-dehydroandrosterone, the alternative chemical designation of dehydroisoandrosterone, under the trade name of " diandrone".

The cases have been grouped in accordance with their type of response to treatment.

\section{Case Reports}

Case 1.-A man, aged 36, was referred by Dr. Gould. The diagnosis was reactive depression in an immature individual of schizothymic temperament. Symptoms included lack of energy, depression, a sense of failure, poorly developed libido, impaired concentration, indecision, feelings of inferiority, shyness, lack of confidence, and apathy. He felt that he was in a mental fog and that life was hard. At his worst moments he was somewhat, but not greatly, relieved by " benzedrine ".

$\mathrm{He}$ was treated with "diandrone", beginning with $5 \mathrm{mg}$. daily : by the fourth day he felt more alert, more active, more "devil-may-care", and less depressed. The dosage was increased to $5 \mathrm{mg}$. twice daily on the 18th day, by which time he was no longer requiring to force himself to perform routine duties and his friends had begun to remark on his improved attitude. Dosage was increased to $5 \mathrm{mg}$. t.i.d. on the 36th day and gradually reduced from the 78th day, by which time libido was increased, he was enjoying dancing, and had found an improvement in his social contacts and interests. His phases of depression, though present, were not disturbing him, and he was finding his work interesting instead of boring as heretofore. Approximately 14 days after reducing dosage he had two bad bouts of depression and was complaining of lack of energy. Two or three days after treatment was stopped altogether he exhibited a "rebound" phenomenon, in which he improved dramatically and felt as well as he had under treatment. This phase lasted about a week. He was then placed on a week's trial of dummy tablets, which he was told were stronger, and reported his surprise and dismay at noticing no improvement. He was given the correct tablets, again $5 \mathrm{mg}$. t.i.d., and improved at once, but reported that this time the improvement was general, rather than specific. A month later he said that he felt well, but that he was needing a lot of sleep. It was obvious that he was somewhat depressed and lacked energy. On the 184th day he reported that he had relapsed, with loss of confidence and depression, and said that he had been under increased domestic stress for the previous two or three weeks. Dosage was increased to $25 \mathrm{mg}$. daily and vitamins exhibited. He improved for four days, then relapsed, but not to his previous low level. Methedrine was given in addition to "diandrone" and vitamins, and the dosage of "diandrone" reduced to $2.5 \mathrm{mg}$. b.d. The patient then became reasonably stable, and remained well on small doses of "diandrone" and "methedrine". 
Fig. 1.-The ratio of neutrophil polymorphonuclear leucocytes to lymphocytes in Case 1.

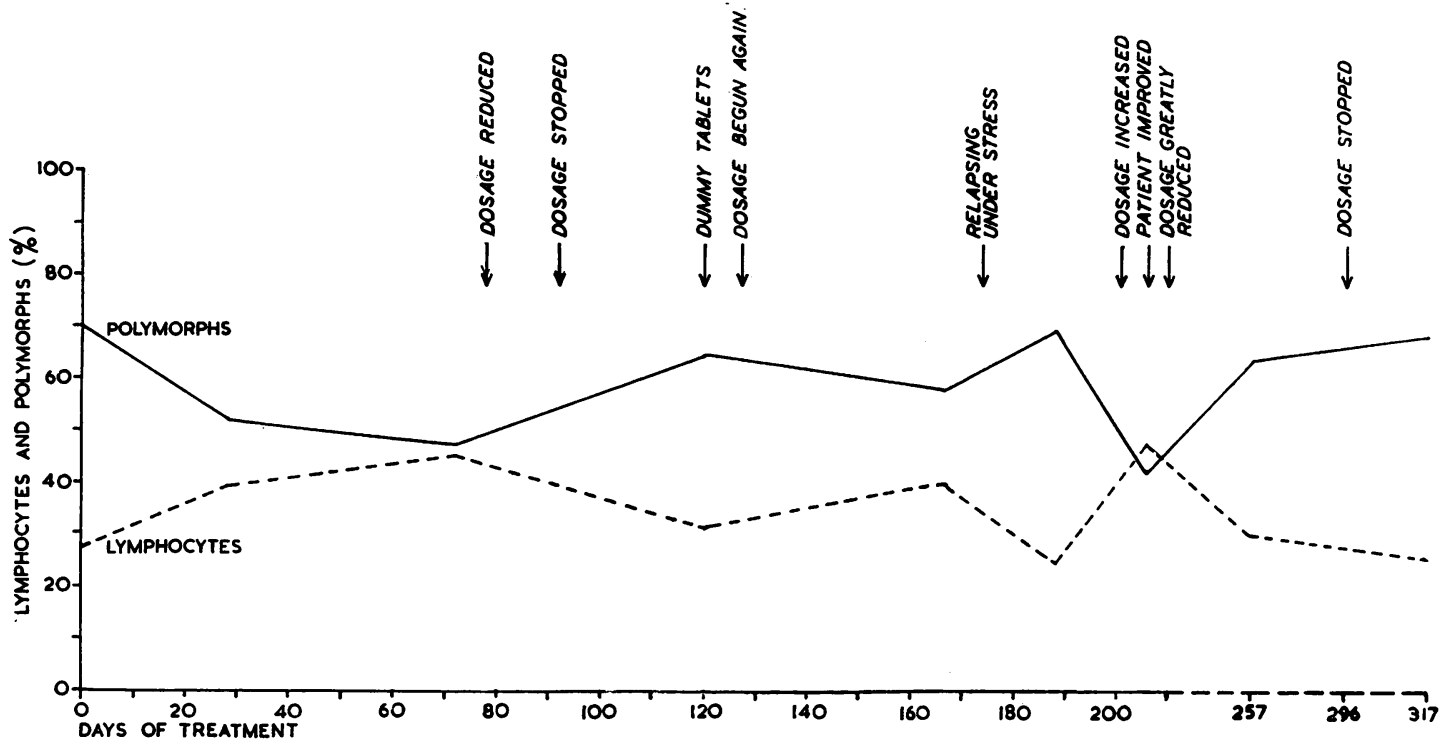

There seemed to be indications that under increased stress dehydroisoandrosterone had lost its effect, as shown by the clinical picture and the alteration in the differential white cell count (Fig. 1). Unfortunately it was not possible to estimate the ketosteroids at this point, and though experimentally perhaps one should have gone on increasing the dose of "diandrone", the condition of the patient, though willing to collaborate, was such that it was better to give amphetamine. The treatment with " diandrone " was continued nevertheless. The patient made a completely satisfactory recovery, which looks like being permanent, as it has been maintained for some considerable time since "diandrone" was discontinued.

Before treatment the patient's total 17-ketosteroid output in 24 hours was $15.6 \mathrm{mg}$., of which the alpha fraction was $83.1 \%$ and the beta fraction $16.9 \%$. After 48 days' treatment the total output was $19.5 \mathrm{mg}$., of which the alpha fraction was $67.7 \%$ and the beta fraction $32 \cdot 3 \%$.

Case 2.-A boy aged 14 was diagnosed as an inadequate schizoid personality. Symptoms included a severe stammer since early childhood, tics and mannerisms for three or four years, timidity, lack of confidence, shyness, inability to " $\mathrm{mix}$ " or play games. In appearance he was undersized and under-weight, and his voice had not yet begun to break.

He received a 65-day course of "diandrone", beginning with a daily dose of $2.5 \mathrm{mg}$. He reported five days later that he could cycle faster. The dose was increased to $5 \mathrm{mg}$. daily, and two days later he found that he stammered less, that he had more energy and was less timid, and that his appetite had increased. The dose was then increased to $10 \mathrm{mg}$. daily. He was reported to be talking more freely and had suddenly discovered that he was good at cricket. His mannerisms and tic: were vanishing. Two days later the dose was increase $\vec{\omega} \vec{\omega}$ to $15 \mathrm{mg}$. daily. By the 29th day of treatment he haf become good all round at games, was anxious not to miss his A.T.C. meetings, had gained in height, no longe政 allowed himself to be bullied and was becoming more self-assertive and rebellious. By the 44th day of treatment he was reported to be over-aggressive, had joined $\overrightarrow{0}$ mischievous gang at school, was talkative in class anis co resentful of any discipline. He appeared to be mildly hypomanic on examination, and investigations revealed that he was in fact taking extra doses of the tablets without the knowledge of his parents; in fact he had been overdosing himself for some time. The daily dose was reduced to $5 \mathrm{mg}$. He became calmer after 10 days and, though he was still difficult to control, the fault lay mainly in mishandling by his parents, who said that, if anything, he now had too much courage ; for example, whereas he had previously been afraid of the shallow end of the swimming bath, he now practised the crawl at the deep end. His stammer had improved considerably. Treatment was stopped altogether ; a rebound phenomenon occurred one week later, and he described himself as even better than when under treatment. After a further week he had settled down at his new level, decided on a career, and become a fit, healthy, ambitious youngster with, however, some residual stammer. He gained considerably in height and half a stone in weight, and developed secondary sexual characteristics. His parents, having expressed their satisfaction with the result obtained, refused to cooperate in further treatment. He was seen again one year later when he had relapsed considerably.

It was not possible to carry out repeated white cell differential counts on this patient, but counts dore before treatment and one before the end of his course 
are well within the normal range and showed no relevant alteration.

His total 17-ketosteroid output in 24 hours before treatment was $4 \mathrm{mg}$. and on the 34 th day $3.85 \mathrm{mg}$.; the alpha and beta fractions were not fully worked out.

Case 3.-A man aged 26 was diagnosed as an inadequate personality. Symptoms were extreme shyness, sexual immaturity, a marked stammer, and nervous blinking which dated from the age of 5 . He had always been timid and lacking in self-confidence, initiative, and drive. He had had about two years of psychotherapy, including hypno-analysis, and his stammer had improved considerably, and he had been able to make friends with a girl. His basic traits had, however, remained unchanged, and a year later he relapsed badly. At this time he had been promoted at work and had become engaged. It was almost impossible for him to use the telephone.

He received systematic treatment, beginning with $5 \mathrm{mg}$. daily. He noticed the effect about an hour or so after the first dose and by the sixth day felt active and confident, and had been able to lose his temper and deal firmly with a junior in the office for the first time in his life. By the 10th day his fiancée had noticed that he was stammering less, had more energy, more confidence, and was speaking better on the telephone. By the 24 th day he had periods when he hardly stammered, and did not mind using the phone. He was realizing how many minor irritations he had had to endure in his domestic setting. It is relevant to note that about the 31st day he began to deteriorate and become depressed. Four days later the dose was increased to $5 \mathrm{mg}$. three times a day. There was a rapid improvement, so that seven days later he reported that he was able to argue on the telephone, even with a senior. On the 67 th day the dose was reduced to $10 \mathrm{mg}$. daily for three days and then $5 \mathrm{mg}$. daily for three days. He had deteriorated by the 74th day, but was still, he said, better than before treatment began. The dose was then reduced to $5 \mathrm{mg}$. 48-hourly and seven days later he reported that he was again unable to use the telephone. Treatment was stopped on the 84th day, and four days later a rebound phenomenon occurred; he felt well, was rather restless, and did not bother to be so obsessionally accurate at work. Fourteen days later, however, he reported that he had relapsed completely, was unable to relax or telephone, and was again stammering badly. He was then placed on dummy tablets and told that they were stronger. He reported after a week's trial that the tablets seemed to have no effect, and he was very worried about it. He was then placed on "diandrone" tablets again and improved at once. His optimum dose was found to be $5 \mathrm{mg}$. twice a day. $\mathrm{He}$ has continued to do well at work, has bought a house, married successfully, and did not stammer during the wedding celebrations, has settled down well, and now has a daughter.

Repeated total and differential white cell counts seemed to show no material alteration in the total count, but there was a slight shift in the relative proportions of the percentage of neutrophil polymorphs to lymphocytes while actually under treatment. This returned to normal when treatment was completed. Before treatment the total white count was 9,000 (polymorphs $61 \%$, lymphocytes $30 \%$, monocytes $7 \%$, eosinophils $2 \%$ ) ; on the 165 th day of treatment it was 8,000 (polymorphs $50 \%$, lymphocytes, $41 \%$ monocytes $8 \%$, eosinophils $1 \%$ ); and, after treatment, 8,600 (polymorphs $67 \%$, lymphocytes $28 \%$, monocytes $5 \%$ ).

The total 17-ketosteroid output in 24 hours before treatment was $13.6 \mathrm{mg}$., of which the alpha fraction was $96 \%$ and the beta fraction $4 \%$, and, after 49 days' treatment, $23.5 \mathrm{mg}$., of which the alpha fraction was $92.5 \%$ and the beta fraction $7 \cdot 5 \%$.

Case 4.-A man aged 20 was diagnosed as a case of reactive depression. Symptoms included pressurefeelings in the head, impaired concentration, inability to carry out his usual tasks without a great effort, and complete loss of confidence.

The patient was placed on "diandrone" empirically and has received 81 days' treatment with $5 \mathrm{mg}$. twice a day. He has, in addition, received thyroid gr. $\frac{1}{2}$ daily. He has noticed steady improvement in his outlook and states that he has more confidence than he ever had. He is now in the Army and is being considered for commissioned rank. He has also succeeded in developing a well mannered resistance to family pressure.

No 17-ketosteroid estimation or blood counts were carried out on this patient.

Case 5.-This was a boy, aged 18, with factors indicating generalized infantilism with hypogonadal features. The diagnosis was schizoid psychopathy. His illness was estimated as lifelong, but the presenting symptoms had originated at the age of 6 . There was an unstable family history and a broken home. Symptoms included fire-raising, and a tendency to run away from home and strip himself naked in the woods. Both symptoms had great sexual significance. He had bizarre religious ideas and was completely unable to adapt himself to everyday life. He had previously been in a mental hospital and had attended special schools. Treatment was begun under the care of Dr. Sands of St. Ebba's Hospital, Epsom. He improved somewhat with educational psychotherapy and testosterone $15 \mathrm{mg}$. daily. He was given "diandrone" $20 \mathrm{mg}$. daily five months later and became more normal in every respect. Confidence, energy, output, and ambition all improved and, though libido began to increase, he lost his urges to express it abnormally. He left hospital two months later and successfully adapted himself both socially and occupationally to life with a farming family. He received a maintenance dose of " diandrone " (10 mg. daily) without any signs of relapse, despite considerable domestic stress from time to time. There is no doubt that this patient, who, despite other forms of treatment, remained on the border-line of schizophrenia, became, after two months' treatment with " diandrone", socially adjusted and has been able to live a reasonably normal, though limited life in a normal family. His case has been followed up for 18 months and he has not relapsed. He continued to do well when medication was stopped. 
White cell counts carried out before treatment showed an average neutrophil polymorph count of $62 \%$ and lymphocytes $30 \%$. In the middle of treatment this had altered to neutrophil polymorphs $52 \cdot 7 \%$, lymphocytes $33.4 \%$, monocytes $3.3 \%$, eosinophils $9.3 \%$, basophils $1.3 \%$, i.e., there was an eosinophilia, but also once again there appeared to be a slight reduction in the percentage of neutrophil polymorphs compared with lymphocytes.

Case 6.-A man aged 30 suffered from a severe obsessional state. There had at one time been some evidence of schizophrenia beneath the surface. The estimated duration of illness was 15 years. He had a relevant family history and an unstable early childhood. He was extremely shy and retarded, both sexually and emotionally. Previous treatment had included approximately a total of four years' psychoanalysis from three different analysts, a full course of insulin coma, electroplexy, electro-narcosis, and reeducative psychotherapy.

The patient was undergoing a course of ether abreaction and was given "diandrone" to encourage his aggressive abreactive patterns, to increase his confidence, and to combat his shyness. The initial daily dose was $5 \mathrm{mg}$. The patient's confidence and libido improved considerably, and he was able to hold his own in one or two unpleasant domestic situations-a thing he had never been able to do previously. He said that he felt more on equal terms with people. Treatment with "diandrone" was terminated when he began to complain of increasing depression. It was considered possible at the time that this might be due to the "diandrone", though the patient was satisfied that the tablets helped him considerably, especially by reducing his fear of people and giving him the confidence to cope with the world better. He had in the course of his treatment found it much easier to approach the opposite sex and had much more desire to do so. Allowance has, of course, to be made for the beneficial effect of the abreactive treatment per se. It is, perhaps, worth noting that a depressive phase coincided with a further course of "diandrone". It is difficult to determine whether there is a causal relationship, as there appears to be in the case of some obsessional patients. The actual effect of the " diandrone" was difficult to assess.

White cell counts were not carried out on this patient, but his total 17-ketosteroid output in 24 hours before treatment was $18.6 \mathrm{mg}$., of which the alpha fraction was $83 \%$ and the beta fraction $17 \%$, and, after approximately 21 days' treatment, the figures were almost unchanged.

Case 7.-This was a man aged 30 with the physical appearance of a boy of 18 and a diagnosis of inadequate psychopathy. Symptoms included extreme shyness, timidity, self-consciousness, lack of ambition, and loneliness. He had made a suicidal attempt while in the army four years before. He had suffered from pulmonary tuberculosis a year before that. His background was without special features.

He was given a course of methyl-testosterone, $10 \mathrm{mg}$. daily, for two weeks without any effect, and six weeks later began a 92-day course of " diandrone", beginning with $5 \mathrm{mg}$. daily. Apart from a slight increase in energy, there was no response, but on the 15th day he was found to have been dissolving the tablets under the tongue. Four days later, having been instructed to swallow the tablets and the dose having been increased to $5 \mathrm{mg}$. three times a day, he thought that his voice was deeper and he felt less shy. By the 29th day he was able to control his blushing and was sure that he had improved a little; and, as he was tending to be irritable, the dose was cut to $5 \mathrm{mg}$. twice daily. Treatment was stopped 14 days later to assess his physical state, and then begun again on the 50th day. He responded very slowly, but became anxious to join a social club and did not feel so nervous. A situation then arose which made it unwise to continue therapy, but the patient, though still limited socially, has continued to improve and has been able to join various clubs and lead a much more active life with a moderate degree of guidance.

Repeated white cell and differential counts were complicated by monocytosis, for which no cause was discovered. The differential count did show a very slight alteration in the neutrophil polymorph/lymphocyte ratio while he was under medication.

The total 17-ketosteroid output in 24 hours before treatment was $12.8 \mathrm{mg}$., of which the alpha fraction was $87.6 \%$ and the beta fraction $12.4 \%$, and after 79 days' treatment the figures were a total output of $11.6 \mathrm{mg}$., of which the alpha fraction was $84 \%$ and the beta fraction $16 \%$.

Case 8. - This was a man aged 46 with a diagnosis of psychosexual impotence in an individual with a ba\& family history. The patient, despite a good educatior and start in life, had never really achieved success is any field. He had ambition, but, as he put it, lackef the drive to achieve his goals. In addition, he was much hindered by a recurrent sexual phantasy which inhibited him in other fields as well. He had been virtually unemployed since the war apart from one or two minor jobs. The patient was treated without success by narco-analysis, testosterone, amphetamine, hypnosis, and was responding slowly to analytical psychotherapy.

In view of the immaturity of his outlook in general, and to his own problems in particular, he was given "diandrone" (10 mg. daily). He reported seven days later that he had more interest in things and that his libido was improving. He found he could discuss his phantasies more easily in the therapeutic session. He decided that they were childish and that he must rid himself of them. The dose was increased to $15 \mathrm{mg}$. daily with increased improvement. He began to take definite steps to get a job at his own intellectual level. On the 34th day of treatment the dose was increased to $20 \mathrm{mg}$. daily. At this dosage level he became overcritical and aggressive towards people who took advantage of him and to whom he had previously been overindulgent. He was aggressive to such an extent that he nearly picked a fight in the street, and his dosage had to be reduced again to $15 \mathrm{mg}$. daily. From the outset of the "diandrone" medication he cooperated 
much more dynamically in his analysis. The patient, having been extremely cynical and critical at the outset, is now extremely enthusiastic about the treatment.

A comparison of the white and differential counts carried out before treatment and on the 72nd day showed once again an alteration in the neutrophil/ lymphocyte ratio.

The total 17-ketosteroid output in 24 hours before treatment was $13.7 \mathrm{mg}$., of which the alpha fraction was $99.3 \%$ and the beta fraction $0.7 \%$. On the 72 nd day the total output had risen to $23 \mathrm{mg}$., of which the alpha fraction was $96.5 \%$ and the beta fraction $3.5 \%$.

Case 9.-This man, aged 39, was diagnosed as an inadequate schizoid psychopath. It was estimated that symptoms had persisted since puberty (age 12 to 14), and included headache, aches in the genitals and stomach, fears, constant tension, a dread of the worries of everyday life. It was felt that these were basically conversion symptoms which excused him from accepting his own inadequacy as a cause of his lack of success. Treatment had been long and varied, including psychoanalysis, hypno-analysis and re-educative psychotherapy by different therapists. There was a constitutional factor and a neurotic background. "Diandrone" was begun with $5 \mathrm{mg}$. daily; four days later he said he felt slowed down, outward tension had slackened, he felt different and on the whole better, but could not explain how. The dose was cut to $2.5 \mathrm{mg}$. daily. Twenty-eight days after treatment began he collapsed into a terror state, stated that he could feel the urge and challenge of life, that it was an upheaval, that he feared the tablets because he realized that he was not yet ready for this access of energy ; it was like putting high-octane fuel into a rickety engine. He responded to reassurance, and mild sedation and stopping " diandrone " treatment, but it is of note that the insight he gained caused great improvement in his therapeutic cooperation, to such an extent that about eight months later he became stabilized sufficiently to admit to a $60 \%$ improvement in all his symptoms. He now only attends occasionally for follow-up.

White cell counts in this patient showed no significant alteration.

The total 17 -ketosteroid output in 24 hours was also within normal limits.

Case 10.-A man aged 24 exhibited acute phobic anxiety and grave motor hysteria. Symptoms included shaking attacks, dyspnoea, an inability to eat in public, to swallow solids, to walk out in the street, or participate in any activity. It was considered that the condition was basically a reaction to a very equivocal home background and certain traumatic experiences. He had had two attacks : the first had cleared quickly following admission to a neurosis centre, the second was of three years' duration and had defied continuous narcesis and other treatments at two different psychiatric hospitals. In view of his lifelong timidity and inadequacy and the total 17-ketosteroid output of $12.7 \mathrm{mg}$., with a beta fraction of only $0.3 \mathrm{mg}$., it was decided to try the effect of "diandrone". He was given a daily dose of $5 \mathrm{mg}$. and responded immediately, being able to walk out in the street and even drive a car for the first time since the illness began. He relapsed, however, by the next evening, but admitted that the tablets had made him feel less frightened and more confident despite himself, and that he now realized that there was a part of him that did not want him to recover. Though " diandrone" treatment was stopped, he cooperated much more fully in his psychotherapeutic sessions thereafter, and improved considerably as a result. We are now of the opinion that "diandrone" should not be used in this type of case, except under strict control and exceptional conditions, because the severity of the anxiety outweighs any advantages to be obtained by forcing the patient to gain an emotionally toned insight too rapidly.

It was impossible to carry out repeated white cell counts on this patient, but those done before and after treatment showed no abnormality.

Case 11.-A man aged 27 was diagnosed as an inadequate psychopath, and it was estimated that he had had symptoms all his life. They included apathy, diminished libido, dyspnoea, migraine, and fatiguability. Before treatment the total 17-ketosteroid estimation was $12 \mathrm{mg}$., of which the alpha fraction was $83 \%$ and the beta fraction $17 \%$. Treatment was begun with $2.5 \mathrm{mg}$. "diandrone" per day, and one week later he had noticed no difference, except that a "benzedrine" tablet that he took had a "wonderful " effect. The dose was increased to $15 \mathrm{mg}$. daily, and the patient, on his own initiative, took up to $30 \mathrm{mg}$. After 22 days' treatment he began to notice some increase in energy and drive, and responded to the challenge with acute migraine. We came to the conclusion that his personality-structure was too poorly integrated for him to be able to benefit from this new source of self-assertiveness and that he was too unreliable and incalculable to justify further treatment with "diandrone" under out-patient conditions. He had a total of 28 days' treatment. It was discovered later that this patient had, in fact, concealed much of his history and past behaviour.

The white cell count carried out on the 26th day of treatment was as follows : total 3,500 (neutrophil polymorphs $47 \%$, lymphocytes $48 \%$, monocytes $4 \%$, eosinophils $1 \%$ ). A repeat count seven days after stopping treatment was total 5,100 (neutrophil polymorphs $64 \%$, lymphocytes $30 \%$, monocytes $2 \%$, eosinophils $3 \%$, basophils $1 \%$ ).

\section{Results of Treatment}

All the 11 cases described above showed some response to "diandrone". The response to very small doses was rapid in Cases 1 to 6 : subjectively, the patients noticed increased confidence, an urge to activity, improvement in libido, increasing interest and awareness of the environment, and an ability to deal with situations which had defeated them in the past. They became less troubled by anxiety in social situations. Objectively, the patients seemed to be less apathetic and more euphoric: 
their attitude became more virile and previously feeble heterosexual interests became greatly strengthened. They appeared to become full of energy and drive. There appeared to be an actual increase in the rate of physical maturation in Case 2.

The response was much slower in Cases 7 and 8 -weeks instead of days-but the objective picture was the same as in the previous cases, although to a lesser extent. It is noteworthy that Case 8 was able to break free from his infantile sexual phantasies, and that Case 7 showed slight evidence of increased physical maturation.

Cases 9, 10, and 11 exhibited a tendency to gross anxiety, hysteria with marked somatic conversion symptoms, and the effect of " diandrone" appeared to be a challenge to which they responded with increased anxiety. However, the treatment did act as a "catalyst", in that psychotherapy started after the treatment was more effective in Cases 9 and 10 than it had been previously.

Neither the weight nor blood pressure was materially altered in any of the above cases. A rebound phenomenon has been noticed in some cases when dosage was being cut down: the patient deteriorated, but two or three days after the final cessation he improved suddenly and dramatically, and remained well for up to a week, when deterioration began again. In some cases, however, including one or two other cases not reported here, the improvement continued, as though the patient had found a new normal level. The rebound phenomenon was associated with increased appetite in the euphoric shape, but a blood sugar curve carried out on one case showed no abnormality. In Case 1 it has been possible to continue after the rebound phenomenon with a much smaller maintenance dose. It is interesting to compare this with the steady deterioration which took place when the dosage was being gradually diminished before actual withdrawal. Furthermore, we noted that the mental state tended to vary with the actual dosage in some individuals. Comparing this with the very large doses which have been used by ourselves and others in different cases, it might be that after a certain point, which varies with each individual, is reached an increase in dosage does not produce any further change.

\section{Changes in the Blood}

There was an alteration in the ratio of lymphocytes to neutrophil polymorphonuclear leucocytes (the $\mathrm{L} / \mathrm{N}$ ratio) in the differential white cell count of some patients. The readings in Case 1 (Fig. 1) in response to stress are especially relevant: it might be that dehydroisoandrosterone has a suppressing effect on some stage of adreno-cortical activity in response to stress; in some of the cases where it was possible to make frequent readings, the neutrophil polymorphonuclear leucocytes diminished in relation to the total count when the patient was receiving dehydroisoandrosterone, and returned to pre-treatment level when dosage was stopped, and this shift appeared to be some indication of response to treatment.

We wish to stress that the above conclusions are only tentative and that more study is needed before any definite statements can be made.

The variation was always well within the normal range, and the type of shift was similar. In no case has there been a pathological drop in the total or specific white counts, and in every case these rapidly returned to pre-treatment levels on dropping "diandrone".

No consistent correlation has yet been found between the alterations in mental state and behaviour and the total 17-ketosteroid output, nor does the ratio between the alpha and beta fractions appear to be very significant, though there may be some importance in the relationship between the amount of alpha-ketosteroid present and the body-weight. We have, however, come to believe that a 17-ketosteroid uutput which is apparently within normal limits is not to be regarded as a contraindication to treatment with dehydroisoandrosterone, if the clinical or Rorschach indications are favourable.

\section{Conclusions}

It is clear that dehydroisoandrosterone altered the behaviour-patterns and mental attitudes in this series of patients, who are probably representative of a small group of persons who exhibit immaturity in one form or another. They are often-probably incorrectly-labelled as inadequate psychopaths, whose response to life is a withdrawal in the direction of schizophrenia, and who have failed to develop satisfactorily either as introverts or as extroverts. All the patients in this series exhibited the schizothymic temperament, in so far as shyness, feebleness of sexual drive, lack of initiative and decisiveness were common characteristics.

Rorschach tests suggest that treatment with "diandrone" enables this group to develop the personality structure which might have been considered to be natural for them.

Dosage should be small in the first instance, $5 \mathrm{mg}$. daily at the most, and, taking the condition of the patient as a guide, gradually increased over the subsequent weeks. Symptoms of over-dosage include restless activity and euphoria, amounting in one case to mild hypomania, and increased aggres- 
siveness, to the point of being quarrelsome and domineering. General experience has shown that there may be a synergistic action with the amphetamines, considerably enhancing the euphoric effect of the latter. Experience showed that if the total daily intake of dehydroisoandrosterone was given in one dose there tended to be a falling off in the effect, with a resulting depression some 10 or 12 hours later. This reaction has been abolished by dividing the daily dose, no matter how small.

The patients who were given dummy tablets noticed the difference, even when led to believe that the inert tablets were, in fact, stronger.

\section{Indications for Treatment}

Individuals similar to the group described above, and the psychotics described in our previous paper (Strauss and others, 1952), are at present the only ones of whom we have direct experience. Dr. Sands, of St. Ebba's Hospital, Epsom, has been working with different age-groups.

Any evidence of antisocial behaviour, sexual or otherwise, and any history of undue aggressiveness and explosiveness is a contraindication to treatment with "diandrone", especially under out-patient conditions.

Fourteen patients were given the Rorschach test by our psychologist, Miss M. Holt, before treatment with dehydroisoandrosterone, and eight afterwards.

The pre-treatment results show evidence of immature personality, poor human and social relationships, schizoid traits, and verbalism.

The patients appeared to conform in showing a constricted and impoverished personality type, such as might come under Rorschach's " coarcted" classification, where both introversive and extroversive tendencies are present to a small extent only. It would appear that the condition termed by Rorschach "ambiequality", in which the patient remains poised, as it were, and unable to develop fully in either direction (little mentioned by any writer) characterizes patients who subsequently improved with " diandrone".

Striking corroboration is also provided by the fact that after treatment the patients show a definite personality swing to one or the other side, i.e., show either marked introversive or extroversive characteristics.

Patients whose personality patterns as exhibited by the Rorschach test have differed markedly from the above and have been given "diandrone", have proved to be unsuitable subjects.

Other points which may prove to be of importance are an increase in the clarity of perceptual appreciation after treatment, which we are now starting to measure, and a change of attitude or orientation towards the same basic concepts still held by the patients, which is of importance in regard to their personality changes.

\section{Discussion and Summary}

Whether "diandrone" turns out to be of therapeutic value in psychiatric practice, taking a longterm view, remains to be seen. Certainly, its random use is bound to give very disappointing results; the case-material has to be selected and controlled with great care and circumspection. However that may be, our research up to date has presented us with quite fascinating problems, for we appear to have at our disposal a chemical agent that can exert a direct and prolonged action on the mental state and may, after protracted use, even initiate subtle changes of a biochemical nature which, in some cases, appear to perpetuate the desired mental improvement after the drug is withdrawn.

The key to the situation is perhaps to be found in the concept of immaturity. Psychiatrists are always using the term in a loose kind of way, sometimes almost as a mild term of abuse, but without very clear ideas as to what constitutes immaturity at the various levels and in the different age-groups.

Recent, as yet unpublished, work in the field of electroencephalography in England has tended to show that electroencephalography can reveal with any certainty as yet only three main types of abnormality : focal lesions, epilepsy, and "immaturity". In fact, all the abnormal E.E.G. patterns that are not quite clearly focal or epileptic seem to indicate immaturity, and the psychiatric investigation of all patients exhibiting those particular aberrant kinds of wave-forms shows them to be "immature" in the sense in which we have used the term throughout this paper.

It has occurred to us that if one cares to review a whole group of abnormal mental states which have heretofore been correctly diagnosed in accordance with valid current concepts, they could perhaps be regarded en masse as varieties of the " immaturity syndrome." Such disorders would include many instances of schizoid psychopathy, schizophrenia-like psychoses of adolescence, retarded puberty, pubertal crises, general " nervousness" manifested as crippling lack of self-confidence, and, possibly, many cases of nocturnal enuresis in older children. If that idea should prove to be well founded and not just wishful thinking, it would suggest that psychogenesis in many of these conditions is of secondary, rather than primary, significance.

Delay in maturation or failure to mature at the various psychosomatic levels coincidentally must 
bring in its wake a certain absence of "vitality" (we are sorry to use so vague a term), a lack of self-confidence leading to inefficacy in dealing with the normal strains and stresses of life, all kinds of secondary psychogenic reaction formations and, in the predisposed, withdrawal from the unequal battle in the direction of schizophrenia (whatever that is). It does, however, seem that we have in "diandrone" a means of treating, anyhow for the time being, some of the grosser features of the immaturity syndrome. At any rate, it provides indications for subsequent research on similar lines by teams of workers-psychiatrists, endocrinologists, and later, perhaps pure biochemists-who have come to understand and sympathize with each other's viewpoint and discipline. A start perhaps has already been made, for a team of clinical and laboratory workers interested in the effect on mental states of changes in the body chemistry is already active. For the moment it has been content to call itself the Psychoendocrine Research Group. It is hoped that observations which will prove of both practical and theoretical value will result from this combined effort.

We acknowledge with gratitude the cooperation and help received from Drs. G. Discombe, J. Gould, H. F. W. Kirkpatrick, A. M. Robinson, L. Rose, D. E. Sands, E. F. Scowen and W. J. Tindall, and Miss M. Holt.

\section{Bibliography}

Reiss, M., Hemphill, R. E., Gordon, J. J., and Cook, E. R. (1949). Biochem. J., 44, 632.

Sackler, M. D., Sackler, R. R., Sackler, A. M., Co Tui, and Ophuijsen, J. $W$ van (1951). Acta psychiat neurol. scand., 26, 415.

Sands, D. E. (1954). J. ment. Sci., 100, 211.

, and Chamberlain, G. H. A.'(1952). Brit. med. J., $2,66$.

Strauss, E. B., Sands, D. E., Robinson, A. M., Tindall, W. J. and Stevenson, W. A. H. (1952). Ibid., 2, 64 . 